the university into an agency of socialization, producing elites armed with certainties, ready answers, and loyalty. Since the region is characterized by social inequality and tensions, counter ideologies hide beneath the surface, waiting for the moment to explode.

DOI: http://dx.doi.org/10.60I7/ihe.2019.97.10938

\section{Forced Internationalization of Higher Education: An Emerging Phenomenon}

\author{
Hakan Ergin, Hans de Wit, and Betty Leask
}

Hakan Ergin is a postdoctoral scholar at the Center for International Higher Education (CIHE), Boston College, US. E-mail: hakan.ergin1@ yahoo.com. Hans de Wit is director of CIHE. E-mail: dewitj@bc.edu. Betty Leask is emerita professor of internationalization at La Trobe University, Melbourne, Australia, and a visiting professor at CIHE. E-mail: leaskb@bc.edu.

$\mathrm{T}$ oday's world is faced with a severe forced migration crisis. The recent Annual Global Trends Report by the United Nations High Commissioner for Refugees (UNHCR) indicates that a person becomes a forced migrant every two seconds. The current number of forced migrants worldwide is 68.5 million. These forced migrants include established scholars as well as undergraduate and graduate students whose education has been interrupted by forces outside of their control. They are knocking on the doors of universities in different parts of the world. Some are being heard, others are being ignored. Universities and governments should remember how significantly forced immigrant scholars and students have contributed to national research and development and institutional quality in the past, including, for example, Jewish scholars who fled to the United States from Nazi Germany.

A recent report by the UNHCR, Left Behind: Refugee Education in Crisis, reveals that the ratio of refugee youth studying at a university is I percent, which is far lower than the global enrollment rate in higher education of 36 percent. It is extremely disappointing that national governments and individual institutions have not acted more quickly to assist the large mass of displaced people in accessing education - in line with Article 26 of the Universal Declaration of Human Rights-thereby recognizing this as a human right. There have been some promising efforts, but these efforts have not been evenly spread across the developed and the developing world. According to the Annual Global Trends Report of the UNHCR, 85 percent of the refugees under the UNHCR's mandate, who have been forcibly displaced as a result of conflict, violence, or persecution, are hosted by countries in the developing world. The challenges faced by these countries in responding to a global problem on their doorstep requires further attention, as the case of Turkey illustrates.

\section{Syrian Refugees in Turkish Universities}

Currently, Turkey hosts over 3.6 million Syrian refugees, the highest number hosted by any country. As the war in Syria is ongoing, and assuming therefore that it will host Syrian refugees for a long time, the Turkish government has repositioned itself by strategically internationalizing three functions of Turkish universities.

In order to help Syrian refugees access universities as students, the Turkish government has reformed academic and financial admission policies. Universities have been required to admit Syrian refugees without proof of previous academic qualification as "special students," and those who do have proof as "regular students." In addition, Arabictaught programs have been established at eight universities in southern Turkey, close to the Syrian border. Financial policies have been changed to provide Syrian refugees with government scholarships and exemption from tuition fees paid by other international students. The result has been a dramatic increase in the number of Syrian students enrolled in Turkish universities, from 608 in 20II to 20,70I in 2018 , as reported by the Council of Higher Education (CoHE).

\section{Currently, Turkey hosts over 3.6 million Syrian refugees, the highest number hosted by any country.}

The strategic internationalization efforts of the Turkish government have also targeted potential academics among Syrian refugees. In 20I6, an online platform, the Database for International Academics, was established to collect curricula vitae. This resulted in increased numbers of Syrian academics working in Turkey. According to the CoHE, the number of full-time Syrian academics has increased from 292 to 348 in the last three years. In addition, in the same period, masters and doctoral programs admitted I,492 and 404 Syrian refugees respectively. 
The Turkish government has also strategically internationalized the public service function of Turkish universities to ensure that Syrian refugees who are neither potential students nor academics are able to access Turkish universities. This has resulted in some Turkish universities offering a range of free services to Syrian refugees. These services include free Turkish language courses, healthcare, psychological support, and information seminars on crucial topics such as childcare, legal rights of refugees, and employability.

\section{FORCED INTERNATIONALIZATION}

The above illustrates an emerging phenomenon, namely forced internationalization. The above-mentioned reforms in Turkey have simultaneously provided forced migrants with access to higher education and internationalized the policies and functions of universities. So what are the key characteristics of forced internationalization? And what does it offer for the future?

Consistent with the existing definition of internationalization of higher education, forced internationalization is intentional, strategic, and it addresses the three core functions of universities: teaching, research, and service. However, it is different in several ways. It responds to a crisis on the doorstep-in Turkey's case, the forced migration of millions of Syrian people, a significant number of whom look to higher education as a pathway to a better life as students, academics, and/or public service recipients. Whereas in the past, internationalization of higher education has primarily been voluntary and part of a deliberate institutional (and in some cases governmental) policy, this emerging form of internationalization is "forced."

Academically, the diversity and brain gain that refugees bring will enhance the quality of learning, teaching, and research, as do other forms of internationalization. Economically, while forced internationalization is unlikely to be a source of income generation in the short term, history tells us that, in the longer term, the innovative and entrepreneurial contributions forced migrants will make to institutions and countries as skilled migrants are substantial. Socially and culturally, forced migrants have the potential to enrich and strengthen the host society. Politically, forced internationalization is a soft power investment, which may lead to improved future diplomatic relations between the host country and the forced migrants' home countries.

In addition to the traditional four rationales for internationalization, forced internationalization demonstrates a new rationale - a "humanitarian rationale," suggested by Streitwieser and his colleagues in 20I8. This rationale recognizes higher education as a public good on a personal level (for the benefit of individuals in need), at the national level (for the benefit of societies and communities within a country) and internationally (for the benefit of the world).

Beyond any doubt, however, integrating a disadvantaged international group into a higher education system creates uncommon challenges. The host society, especially where access to university is highly competitive, may resist this type of internationalization, regarding the forced migrants as competitors with an unfair advantage. Formulating and passing controversial laws is a legal challenge. Forced migrants often need not only exemption from tuition fees, but also direct financial aid, posing an economic challenge. Administratively, it can also be difficult to assess forced migrants' previous qualifications. Forced migrants need access to information about applying to universities, which creates communication challenges. A language-related obstacle is that most forced migrants lack proficiency in the host country's official language. Forced internationalization is in many ways a race against time, requiring a host country to act swiftly in order to find and support the best talents among the refugee population.

Despite these challenges, we suggest that forced internationalization driven by a humanitarian rationale offers a positive response to forced migration. Applied globally, "forced internationalization" would see governments and universities across the world internationalizing in new ways, in places far away from those affected by crises in geographic terms, but close to them in humanitarian terms.

DOI: http://dx.doi.org/Io.6oI7/ihe.20I9.97.10938

\section{How Is Academic Culture Influenced by International- ization?}

\section{Milena Benítez}

Milena Benitez is a doctoral candidate at the Pontifical Catholic University of Chile and a visiting scholar at the Center for International Higher Education (CIHE) at Boston College, US. E-mail: mbenitez2@ uc.cl.

T n a globalized world, higher education systems (i.e., uni1 versities and colleges) integrate international practices into teaching and learning processes, research, and admin- 